\title{
Mini-Review of Studies Reporting the Repeatability and Reproducibility of Diffusion Tensor Imaging
}

Investigative Magnetic Resonance Imaging

\section{Review Article}

Received: December 31, 2018

Revised: January 23, 2019

Accepted: February 1, 2019

\section{Correspondence to:}

Sung Ho Jang, M.D.

Department of Physical Medicine and Rehabilitation, College of Medicine, Yeungnam University, 317-1, Daemyung-dong, Nam-gu, Daegu 42415, Korea.

Tel. +82-53-620-3269

Fax. +82-53-620-3269

E-mail: strokerehab@hanmail.net

\author{
Jeong Pyo Seo, Young Hyeon Kwon, Sung Ho Jang \\ Department of Physical Medicine and Rehabilitation, College of Medicine, Yeungnam University, \\ Daegu, Korea
}

Purpose: Diffusion tensor imaging (DTI) data must be analyzed by an analyzer after data processing. Hence, the analyzed data of DTI might depend on the analyzer, making it a major limitation. This paper reviewed previous DTI studies reporting the repeatability and reproducibility of data from the corticospinal tract (CST), one of the most actively researched neural tracts on this topic.

Materials and Methods: Relevant studies published between January 1990 and December 2018 were identified by searching PubMed, Google Scholar, and MEDLINE electronic databases using the following keywords: DTI, diffusion tensor tractography, reliability, repeatability, reproducibility, and CST. As a result, 15 studies were selected. Results: Measurements of the CSTs using region of interest methods on 2-dimensional DTI images generally showed excellent repeatability and reproducibility of more than 0.8 but high variability ( 0.29 to 1.00$)$ between studies. In contrast, measurements of the CST using the 3-dimensional DTT method not only revealed excellent repeatability and reproducibility of more than 0.9 but also low variability (repeatability, 0.88 to 1.00; reproducibility, 0.82 to 0.99 ) between studies.

Conclusion: Both 2-dimensional DTI and 3-dimensional DTT methods appeared to be reliable for measuring the CST but the 3-dimensional DT method appeared to be more reliable.

Keywords: Diffusion tensor imaging; Diffusion tensor tractography; Corticospinal tract; Repeatability; Reproducibility

\section{INTRODUCTION}

Diffusion tensor imaging (DTI) provides valuable information on the subcortical white matter that is unavailable with conventional CT and MRI. Therefore, the development of DTI in the 1990s led to a new era for examination of the subcortical white matter in live human brains (1). In addition, diffusion tensor tractography (DTT), which is reconstructed from DTI data, is used to visualize and estimate the neural tracts in the subcortical white matter of the brain $(2,3)$. As a result, DTI has contributed to the revolutionary development of neuroscience. For example, it allows the detection of brain lesions, which are undetectable by conventional MRI in various brain pathologies, including axonal injury in a concussion, stroke, hypoxic-ischemic brain injury, and cerebral palsy (4-7). 
Because DTI data must be analyzed by an analyzer (operator) after data processing, the results may depend on the analyzer, making it a major limitation $(8,9)$. To address this possible limitation, many studies have reported the repeatability and reproducibility of analyzed DTI data (10-24). The analyses methods for DTI data can be grossly classified into two methods: 1) a 2-dimensional DTI method using the region of interest (ROI), which involves measurements of the DTI parameters in a certain ROI on a 2-dimensional DTI image of the brain (Fig. 1a); and 2) a 3-dimensional DTT method for neural tracts (10-24) (Fig. 1b). Because the placement of an ROI in a certain brain area by an analyzer might be inaccurate and subjective,

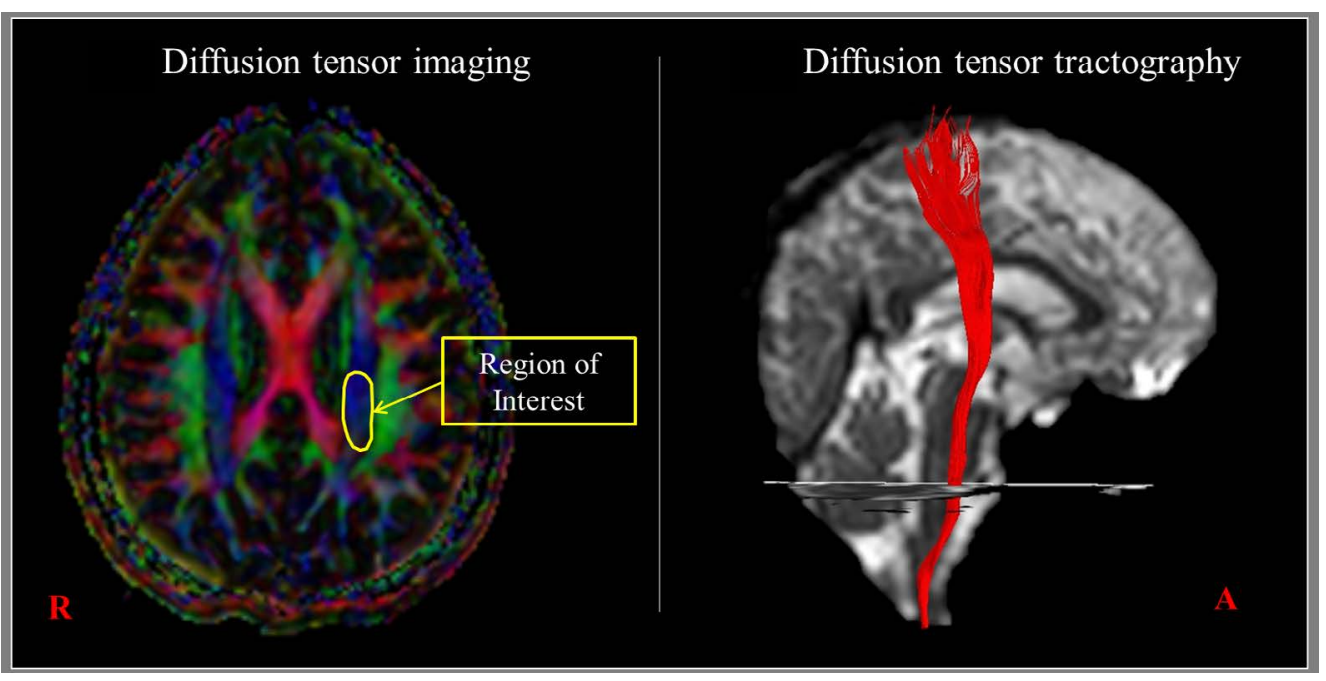

a

b

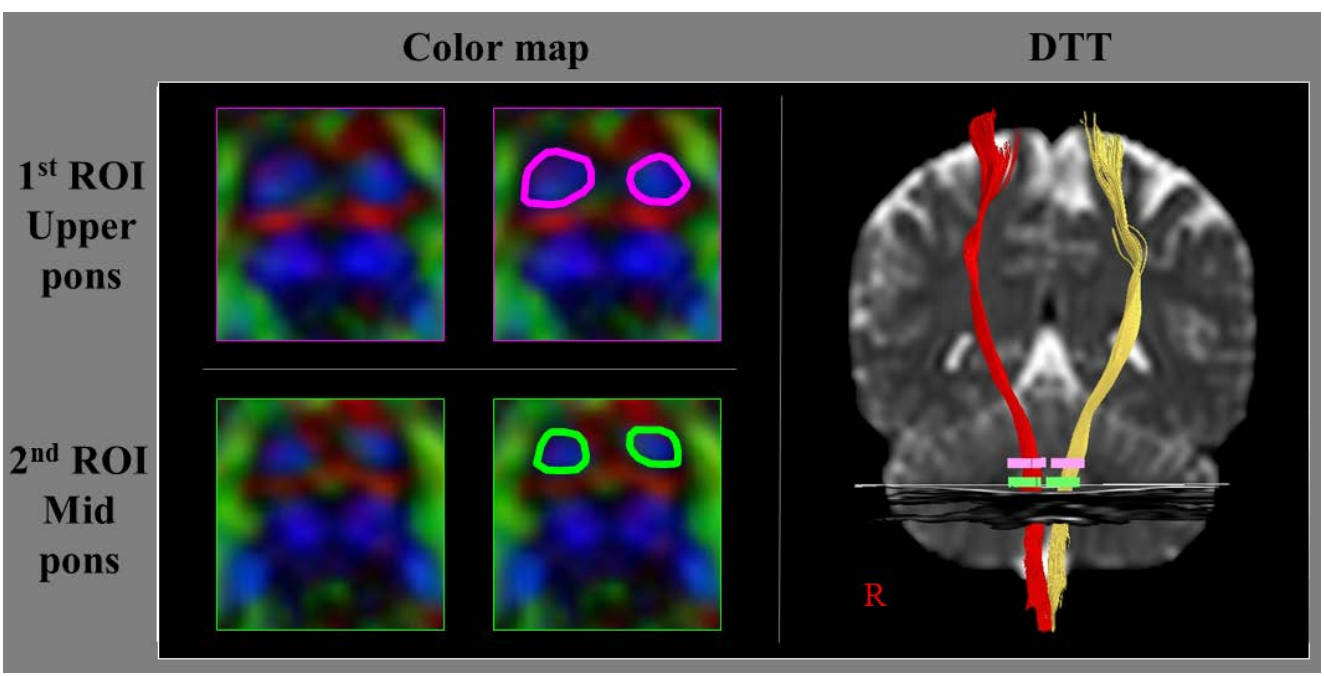

a the results may vary (Fig. 2a). This might result in low repeatability, low reproducibility, and high variation of the analyzed DTI data $(11,14,15,22)$. In contrast, DT can show excellent repeatability, excellent reproducibility, and low variation of analyzed DTI data because the application methods involving ROls and the analytical conditions are well-defined in many neural tracts of the brain $(10,12,13$, 16-21, 23-25) (Fig. 2b).

This paper reviewed DTI studies reporting the repeatability and reproducibility of measurements of the corticospinal tract (CST), which is one of the most actively researched neural tracts on this topic (10-24).
Fig. 1. Measurement of parameters using the region of interest on diffusion tensor imaging (a) and using the reconstructed corticospinal tract on diffusion tensor tractography (b).
Fig. 2. (a) First and second regions of interest (ROls: roundly drawn area) are applied to the corticospinal areas in the upper pons and mid-pons, respectively. (b) The reconstructed corticospinal tracts that are commonly passed through the first and second ROIS. 


\section{MATERIALS AND METHODS}

Relevant studies from January 1990 to December 2018 were identified by searching PubMed, Google Scholar, and MEDLINE electronic databases using the following keywords/abbreviations: DTI, DT, reliability, repeatability, reproducibility, and CST. This review was limited to studies of humans and relevant studies were selected according to the flow diagram presented in Figure 3 (first selection keyword, DTI or DT; second selection keyword, reliability or repeatability or reproducibility; and exclusion criteria, not related the CST). As a result, 15 studies were reviewed (1024) (Table 1).

\section{RESULTS}

\section{Repeatability and Reproducibility of Diffusion Tensor Imaging}

Since the introduction of DTI, many studies have reported the repeatability and/or reproducibility of DTI for the CST (10-24). Among these studies, four studies examined the CST using the intra-class correlation coefficient (ICC) (11, 14, 15, 22). In 2007, Bonekamp et al. (11) measured the fractional anisotropy (FA) and apparent diffusion coefficient (ADC) at several ROls that the CST passes through, the cerebral peduncle, the posterior limb of the internal capsule, and the superior corona radiata in 40 normal children. They reported substantial to excellent repeatability and reproducibility in the FA and ADC values at each ROI (ICC, 0.66 to 0.99) (11). In 2012, Borich et al. (14) reported substantial to excellent repeatability and reproducibility of DTI by measuring the FA of the posterior limb of the internal capsule in ten chronic stroke patients (ICC, 0.76 to 0.94 ). During the same year, Hakulinen et al. (15) reported the repeatability of DTI using two other methods of setting the ROI (circular and freehand) in 30 normal subjects and found substantial to excellent repeatability in the FA and ADC (ICC, 0.63 to 0.90). In 2017, Acheson et al. (22) examined the reproducibility of DTI using the ICC between interscans of DTI in 12 normal adult subjects and 89 children and adolescents and demonstrated substantial to excellent reproducibility in the FA of the posterior limb of the internal capsule and corona radiata (ICC, 0.72 to 0.87 ).

\section{Repeatability and Reproducibility of Diffusion Tensor Tractography}

Eleven studies have reported the repeatability and/or reproducibility of 3-dimensionally reconstructed CST using the DIT method. Seven studies used the ICC, two studies employed the Kappa value, and two studies used the chisquared test and coefficients of variation $(10,12,13,16-$

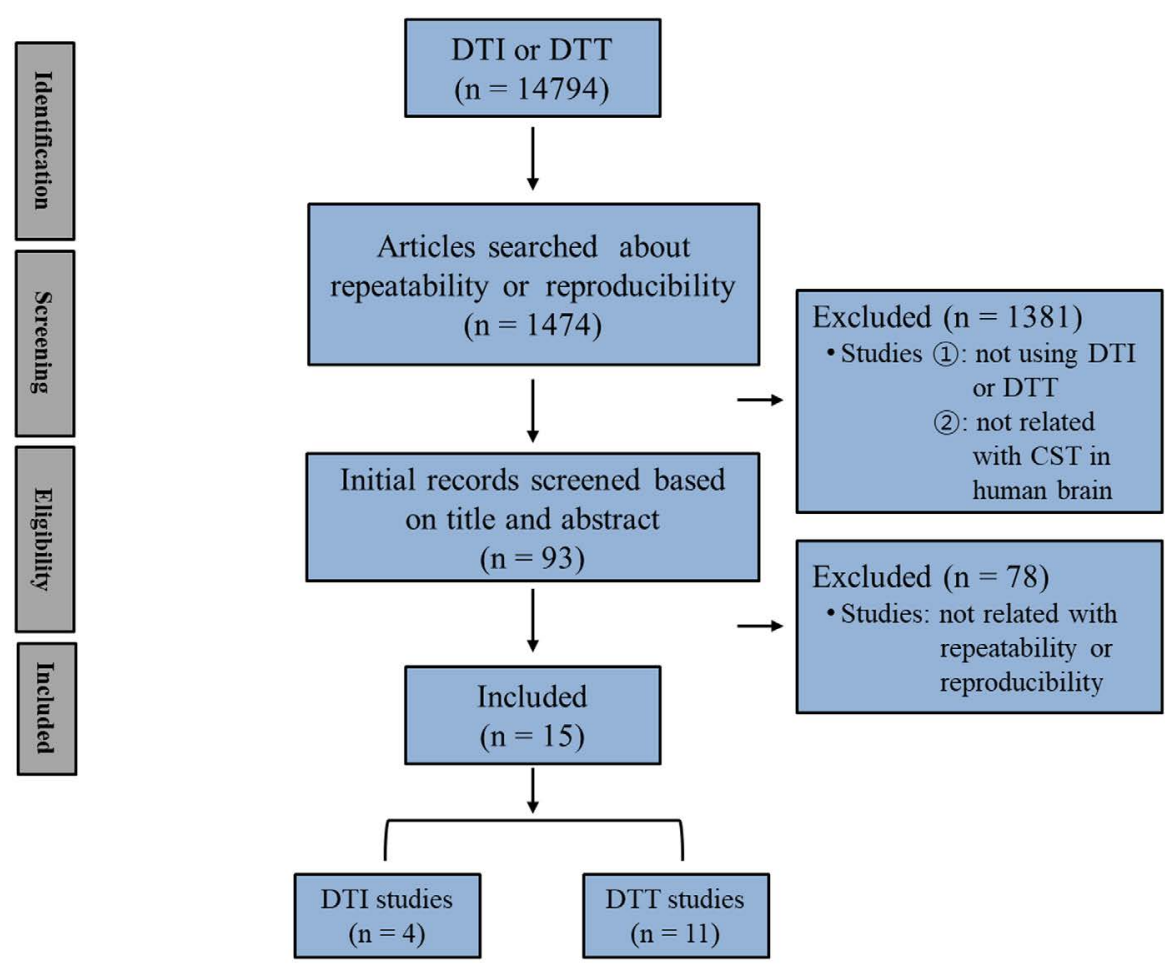

Fig. 3. Flow diagram of the approach used to select the studies to be reviewed. 
Table 1. Repeatability and Reproducibility of Diffusion Tensor Imaging and Diffusion Tensor Tractography of the Corticospinal Tract

\begin{tabular}{|c|c|c|c|c|c|c|}
\hline Authors & $\begin{array}{c}\text { Publication } \\
\text { year }\end{array}$ & Subjects no. & $\begin{array}{l}\text { Statistical } \\
\text { analysis }\end{array}$ & Repeatability & Reproducibility & Region of interest \\
\hline \multirow{19}{*}{$\begin{array}{c}\text { DTI Bonekamp et } \\
\text { al. (11) }\end{array}$} & 2007 & 40 healthy children & ICC & Intra-raters & Inter-raters & 1. Cerebral peduncle \\
\hline & & & & $\begin{array}{c}\text { 1. CP } \\
F A-I C C: 0.96\end{array}$ & $\begin{array}{c}\text { 1. CP } \\
F A-I C C: 0.90\end{array}$ & $\begin{array}{l}\text { 2. Posterior limb of internal } \\
\text { capsule }\end{array}$ \\
\hline & & & & ADC - ICC: 0.98 & ADC - ICC: 0.92 & 3. Superior corona radiata \\
\hline & & & & 2. PLIC & 2. PLIC & \\
\hline & & & & FA - ICC: 0.97 & FA - ICC: 0.91 & \\
\hline & & & & ADC - ICC: 0.99 & ADC - ICC: 0.98 & \\
\hline & & & & 3. SCR & 3. SCR & \\
\hline & & & & FA - ICC: 0.99 & FA - ICC: 0.97 & \\
\hline & & & & ADC - ICC: 1.00 & ADC - ICC: 0.99 & \\
\hline & & & & & Inter-scans & \\
\hline & & & & & 1. $\mathrm{CP}$ & \\
\hline & & & & & FA - ICC: 0.81 & \\
\hline & & & & & ADC - ICC: 0.86 & \\
\hline & & & & & 2. PLIC & \\
\hline & & & & & FA - ICC: 0.66 & \\
\hline & & & & & ADC - ICC: 0.82 & \\
\hline & & & & & 3. SCR & \\
\hline & & & & & FA - ICC: 0.79 & \\
\hline & & & & & ADC - ICC: 0.93 & \\
\hline $\begin{array}{l}\text { Borich et al. } \\
\qquad(14)\end{array}$ & 2012 & $\begin{array}{l}10 \text { chronic stroke } \\
\text { patients } 10 \text { healthy } \\
\text { adults }\end{array}$ & ICC & $\begin{array}{l}\text { Intra-raters } \\
\text { FA - ICC: } 0.94\end{array}$ & $\begin{array}{l}\text { Inter-raters } \\
\text { FA - ICC: } 0.71\end{array}$ & $\begin{array}{l}\text { Posterior limb of internal } \\
\text { capsule }\end{array}$ \\
\hline $\begin{array}{l}\text { Hakulinen et } \\
\text { al. (15) }\end{array}$ & 2012 & 30 healthy adults & ICC & $\begin{array}{l}\text { Circular ROI } \\
\text { 1. Pons }\end{array}$ & & 1. Pons \\
\hline
\end{tabular}

$\begin{array}{cc}\text { FA - ICC: } 0.74 & \text { 2. Cerebral peduncle } \\ \text { ADC - ICC: } 0.83 & \text { 3. Posterior limb of interna } \\ \text { 2. CP } & \text { capsule } \\ \text { FA - ICC: } 0.74 & \text { 4. Corona radiate } \\ \text { ADC - ICC: } 0.19 & \text { 5. Centrum semiovale } \\ \text { 3. PLIC } & \end{array}$

$$
\begin{gathered}
\text { FA - ICC: } 0.90 \\
\text { ADC - ICC: } 0.76
\end{gathered}
$$$$
\text { 4. } C R
$$$$
\text { FA - ICC: } 0.84
$$$$
\text { ADC - ICC: } 0.76
$$

Freehand ROI

1. Pons

FA - ICC: 0.63

ADC - ICC: 0.70 


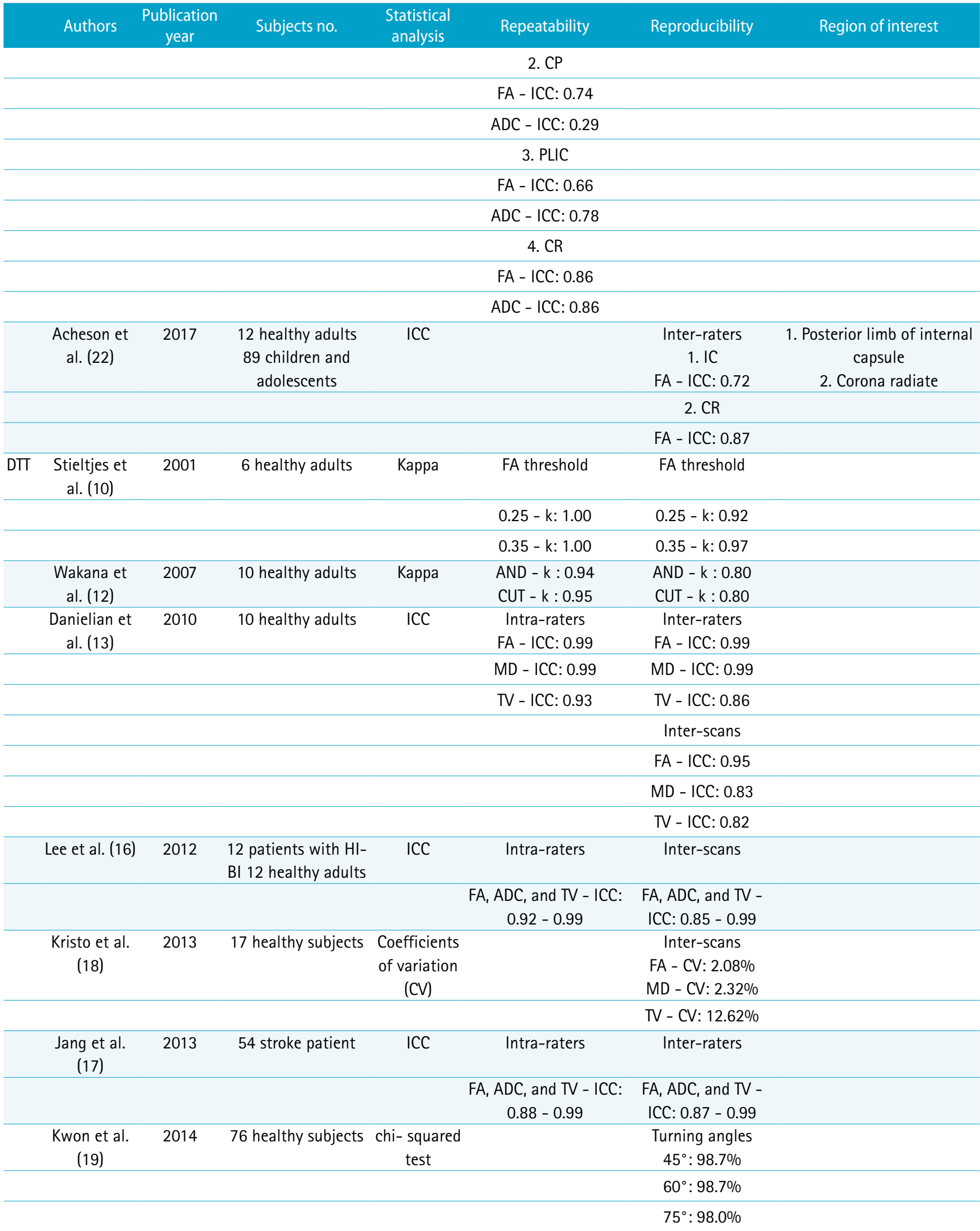




\begin{tabular}{|c|c|c|c|c|c|c|}
\hline Authors & $\begin{array}{c}\text { Publication } \\
\text { year }\end{array}$ & Subjects no. & $\begin{array}{c}\text { Statistical } \\
\text { analysis }\end{array}$ & Repeatability & Reproducibility & Region of interest \\
\hline \multirow[t]{2}{*}{$\begin{array}{l}\text { Paldino et al. } \\
\text { (20) }\end{array}$} & 2014 & 30 pediatric patients & ICC & & $\begin{array}{l}\text { Inter-raters } \\
\text { FA - ICC: } 0.99\end{array}$ & \\
\hline & & & & & MD - ICC: 0.97 & \\
\hline $\begin{array}{l}\text { Rijken et al. } \\
\text { (21) }\end{array}$ & 2015 & $\begin{array}{l}7 \text { healthy subjects } \\
58 \text { patients with } \\
\text { craniosynostosis } \\
\text { syndromes }\end{array}$ & ICC & $\begin{array}{c}\text { Intra-raters } \\
\text { FA, ADC, and TV - ICC: } \\
0.93\end{array}$ & $\begin{array}{l}\text { Inter-raters } \\
\text { FA, ADC, and TV - } \\
\text { ICC: } 0.94\end{array}$ & \\
\hline lus et al. (23) & 2017 & $\begin{array}{l}37 \text { patients with } \\
\text { low-grade glioma }\end{array}$ & ICC & & $\begin{array}{l}\text { Inter-raters } \\
\text { TV - ICC: } 0.99\end{array}$ & \\
\hline \multirow[t]{5}{*}{$\begin{array}{l}\text { Rosenstock } \\
\text { et al. (24) }\end{array}$} & 2017 & $\begin{array}{l}30 \text { patients with } \\
\text { high grade glioma }\end{array}$ & ICC & & $\begin{array}{c}\text { Distance between } \\
\text { tumor and CST }\end{array}$ & \\
\hline & & & & & - ICC: 0.99 & \\
\hline & & & & & FA - ICC: 0.94 & \\
\hline & & & & & ADC - ICC: 0.96 & \\
\hline & & & & & TV - ICC: 0.90 & \\
\hline
\end{tabular}

$21,23,24)$. In 2001, Stieltjes et al. (10) reported "almost perfect" repeatability and reproducibility of DT for the CST in six normal subjects using the Kappa value, which were determined for spatially superimposed images (k-value, 0.92 to 1.00). In 2007, Wakana et al. (12) demonstrated "substantial" repeatability and reproducibility of the CST using pair-wise combinations via the Kappa value in ten normal subjects (k-value, 0.79 to 0.80 ). In 2010, Danielian et al. (13) measured the DTT parameters (the FA, mean diffusivity [MD], and tract volume [TV]) of the CST, and obtained excellent repeatability and reproducibility using the ICC (intra-rater ICC, 0.93 to 0.99; inter-raters ICC, 0.86 to 0.99; inter-scans ICC, 0.82 to 0.95). In 2012, Lee et al. (16) reported excellent repeatability and reproducibility of the DTT parameters (the FA, ADC, and TV) of the CST in 12 patients with hypoxic-ischemic brain injury (intra-rater ICC, 0.92 to 0.99 ; inter-raters ICC, 0.85 to 0.99 ). In 2013, Kristo et al. (18) investigated the reproducibility of measurements of the DTT parameters (the FA, MD, and TV) in the CST for twice-scanned data in 17 normal subjects and found low architectural and microstructural variability in the DT parameters (the FA and MD) using the coefficients of variation ( $C V, 0.87$ to 3.37). During the same year, Jang et al. (17) reported the excellent repeatability and reproducibility of DTT using DTT parameters (FA, ADC, and TV) of the reconstructed CST in 54 stroke patients using the ICC (intrarater ICC, 0.88 to 0.99; inter-raters ICC, 0.87 to 0.99). In 2014, Kwon et al. (19) examined the reproducibility via the incidence of transcallosal motor fibers using a chi-squared test in the reconstructed CST for 76 normal subjects and found no significant difference between the three tractturning angles $\left(45^{\circ}, 60^{\circ}\right.$, and $\left.75^{\circ}\right)$. They reported excellent reproducibility of the reconstruction rate, at 98.0 to 98.7 percent (19). In 2015, Rijken et al. (21) reported excellent repeatability and reproducibility using DTT parameters (the $F A, A D C$, and TV) of the CST in seven normal subjects and 58 patients with craniosynostosis syndromes using the ICC (intra-rater ICC, 0.93; inter-raters ICC, 0.94). Recently, lus et al. (23) demonstrated excellent reproducibility in the TV value for the CST in 37 patients with low-grade glioma using the ICC (inter-rater ICC, 0.99). During the same year, Rosenstock et al. (24) measured the DT parameters (the FA, $A D C$, and TV) and the closest distance between the tumor and the CST in 30 patients with high-grade gliomas, and demonstrated excellent reproducibility via the ICC (interraters ICC, 0.90 to 0.99).

\section{DISCUSSION and CONCLUSION}

This paper reviewed 15 DTI studies reporting the repeatability and reproducibility of the CST. A summary of the results follows. Measurements of the CST using the ROI method on 2-dimensional DTI generally showed excellent repeatability and reproducibility of more than 0.8 with high variability $(0.29$ to 1.00$)$ between studies $(11,14$, 
$15,22)$. In contrast, measurements of the CST using the 3-dimensional DTT method revealed excellent repeatability and reproducibility of more than 0.9 with low variability (repeatability, 0.88 to 1.00 ; reproducibility, 0.82 to 0.99 ) between studies $(10,12,13,16-21,23,24)$. As a result, both methods for measuring the CST appeared to be reliable but the 3-dimensional DT method was more reliable than the 2-dimensional DTI method (10-24).

The above results can be attributed to several factors. Accurate placing of the ROIs on the 2-dimensional DTI image repeatedly is difficult, both in intra-analyzer and inter-analyzer tests. In addition, the anatomical location of the CST varies between individual subjects $(26,27)$ (Fig. 1a). In contrast, in 3-dimensional DT for the CST, analysis of the CST using the combined conditions of multiple ROls on the isolated CST areas with known analysis conditions (FA and angle change between pixels) can reconstruct the CST more objectively and accurately with less subjective error than the 2-dimensional DTI method (10,12, 13, 16-21, 23-25) (Fig. 1b).

In conclusion, both the 2- and 3-dimensional DTI methods appeared to be reliable for measuring the CST. On the other hand, the 3-dimensional DT method appeared to be more reliable than the 2-dimensional DTI method. However, repeatability and reproducibility were affected by scanning conditions, including gradient directions and the number of excitations (28). Further studies on the optimal conditions for the number and anatomical locations of ROls are needed to achieve better repeatability and reproducibility of the CST measurements.

\section{Acknowledgments}

This research was supported by the Basic Science Research Program through the National Research Foundation of Korea (NRF) funded by the Ministry of Education (NRF-2016R1A6A3A11933121).

\section{REFERENCES}

1. Basser PJ, Mattiello J, LeBihan D. MR diffusion tensor spectroscopy and imaging. Biophys J 1994;66:259-267

2. Mori S, Crain BJ, Chacko VP, van Zijl PC. Three-dimensional tracking of axonal projections in the brain by magnetic resonance imaging. Ann Neurol 1999;45:265-269

3. Basser PJ, Pajevic S, Pierpaoli C, Duda J, Aldroubi A. In vivo fiber tractography using DT-MRI data. Magn Reson Med
2000;44:625-632

4. Wang JY, Bakhadirov K, Devous MD Sr, et al. Diffusion tensor tractography of traumatic diffuse axonal injury. Arch Neurol 2008;65:619-626

5. Shenton ME, Hamoda HM, Schneiderman JS, et al. A review of magnetic resonance imaging and diffusion tensor imaging findings in mild traumatic brain injury. Brain Imaging Behav 2012;6:137-192

6. Jang SH. Traumatic axonal injury in mild traumatic brain injury. In: Gorbunoy N, ed. Traumatic brain injury. 1st ed. London: InTech, 2018:137-154

7. Yu FF, Chiang FL, Stephens N, et al. Characterization of normal-appearing white matter in multiple sclerosis using quantitative susceptibility mapping in conjunction with diffusion tensor imaging. Neuroradiology 2019;61:71-79

8. Lee SK, Kim DI, Kim J, et al. Diffusion-tensor MR imaging and fiber tractography: a new method of describing aberrant fiber connections in developmental CNS anomalies. Radiographics 2005;25:53-65; discussion 6658

9. Yamada K, Sakai K, Akazawa K, Yuen S, Nishimura T. MR tractography: a review of its clinical applications. Magn Reson Med Sci 2009;8:165-174

10. Stieltjes B, Kaufmann WE, van Zijl PC, et al. Diffusion tensor imaging and axonal tracking in the human brainstem. Neuroimage 2001;14:723-735

11. Bonekamp D, Nagae LM, Degaonkar M, et al. Diffusion tensor imaging in children and adolescents: reproducibility, hemispheric, and age-related differences. Neuroimage 2007;34:733-742

12. Wakana S, Caprihan A, Panzenboeck MM, et al. Reproducibility of quantitative tractography methods applied to cerebral white matter. Neuroimage 2007;36:630644

13. Danielian LE, Iwata NK, Thomasson DM, Floeter MK. Reliability of fiber tracking measurements in diffusion tensor imaging for longitudinal study. Neuroimage 2010;49:1572-1580

14. Borich MR, Wadden KP, Boyd LA. Establishing the reproducibility of two approaches to quantify white matter tract integrity in stroke. Neuroimage 2012;59:2393-2400

15. Hakulinen U, Brander A, Ryymin P, et al. Repeatability and variation of region-of-interest methods using quantitative diffusion tensor MR imaging of the brain. BMC Med Imaging 2012;12:30

16. Lee AY, Shin DG, Park JS, et al. Neural tracts injuries in patients with hypoxic ischemic brain injury: diffusion tensor imaging study. Neurosci Lett 2012;528:16-21

17. Jang SH, Chang CH, Lee J, Kim CS, Seo JP, Yeo SS. Functional role of the corticoreticular pathway in chronic 
stroke patients. Stroke 2013;44:1099-1104

18. Kristo $G$, Leemans $A$, de Gelder $B$, Raemaekers $M$, Rutten GJ, Ramsey N. Reliability of the corticospinal tract and arcuate fasciculus reconstructed with DTI-based tractography: implications for clinical practice. Eur Radiol 2013;23:28-36

19. Kwon HG, Son SM, Jang SH. Development of the transcallosal motor fiber from the corticospinal tract in the human brain: diffusion tensor imaging study. Front Hum Neurosci 2014;8:153

20. Paldino MJ, Hedges $K$, Rodrigues KM, Barboriak DP. Repeatability of quantitative metrics derived from MR diffusion tractography in paediatric patients with epilepsy. Br J Radiol 2014;87:20140095

21. Rijken $B F$, Leemans $A$, Lucas $Y$, van Montfort $K$, Mathijssen $I M$, Lequin $M H$. Diffusion tensor imaging and fiber tractography in children with craniosynostosis syndromes. AJNR Am J Neuroradiol 2015;36:1558-1564

22. Acheson A, Wijtenburg SA, Rowland LM, et al. Reproducibility of tract-based white matter microstructural measures using the ENIGMA-DTI protocol. Brain Behav 2017;7:e00615

23. Ius $T$, Turella $L$, Pauletto $G$, et al. Quantitative diffusion tensor imaging analysis of low-grade gliomas: from preclinical application to patient care. World Neurosurg 2017;97:333-343

24. Rosenstock T, Giampiccolo D, Schneider H, et al. Specific DTI seeding and diffusivity-analysis improve the quality and prognostic value of TMS-based deterministic DTI of the pyramidal tract. Neuroimage Clin 2017;16:276-285

25. Kunimatsu A, Aoki S, Masutani Y, et al. The optimal trackability threshold of fractional anisotropy for diffusion tensor tractography of the corticospinal tract. Magn Reson Med Sci 2004;3:11-17

26. Seo JP, Chang PH, Jang SH. Anatomical location of the corticospinal tract according to somatotopies in the centrum semiovale. Neurosci Lett 2012;523:111-114

27. Kwon HG, Yang JH, Park JB, Kim MH, Choi SH, Yang DS. Anatomical location and somatotopic organization of the corticospinal tract in the corona radiata of the normal human brain: a diffusion tensor tractography study. Neuroreport 2014;25:710-714

28. Wang JY, Abdi H, Bakhadirov K, Diaz-Arrastia R, Devous MD Sr. A comprehensive reliability assessment of quantitative diffusion tensor tractography. Neuroimage 2012;60:11271138 